\title{
Habitat bottlenecks in stage-structured species: hermit crabs as a model system
}

\author{
Benjamin S. Halpern ${ }^{1,2, *}$ \\ ${ }^{1}$ Long Marine Laboratory, 100 Shafer Road, University of California, Santa Cruz, California 95060, USA \\ ${ }^{2}$ Present address: National Center for Ecological Analysis and Synthesis, 735 State Street, Santa Barbara, \\ California 93101, USA
}

\begin{abstract}
The availability of habitat at one stage of a species' life history may limit the ultimate population size of that species. In particular, species that use distinct juvenile habitats may experience bottlenecks at an early life stage that have important and potentially unexpected consequences for adult population sizes. I used intertidal hermit crabs Pagurus samuelis and P. hirsuitisculus as a model system to test experimentally the effect of increasing juvenile and adult habitat (snail shells, Littorina sp. and Tegula funebralis) availability on adult population size. Despite strong evidence from these experiments that juvenile hermit crab population size was limited by juvenile habitat availability, adult population size was not. Instead, results indicated that adult populations were probably limited by recruitment and adult habitat availability. Consequently, these results (1) demonstrate that identifying true habitat bottlenecks can be challenging, (2) show that identifying true bottlenecks requires one to evaluate the effect of bottlenecks on adult population size, and (3) offer a rigorous empirical test of the assumption that hermit crab populations are limited by the availability of large shells. These results also highlight how conservation and management strategies designed to protect species with stage-structured life histories must consider the actual role different habitats play in controlling adult population size if they are to be most effective.
\end{abstract}

KEY WORDS: Population bottlenecks · Juvenile habitat · Nursery habitat · Population limitation · Hermit crabs $\cdot$ Recruitment limitation

\section{INTRODUCTION}

One of the major goals in the field of ecology is to determine what limits or regulates the size of a population. When such limiting factors or processes act at a particular stage of a species' life cycle, the population is typically described as having gone through a bottleneck. In other words, changes in the extent of some limiting factor or process cause ultimate (adult) population sizes to change in a similar fashion. Past work has led to a proliferation of 'bottleneck hypotheses' that attribute stage-specific reductions in population size to a variety of abiotic and biotic factors (Fretwell 1972, Weins 1977, Caddy 1986, Werner 1986, Moran \& Whitham 1988, DeMartini \& Roberts 1990, Holbrook et al. 1990, Persson \& Greenberg 1990, Unger \& Lewis
1991, Wahle \& Steneck 1991, Nillson 1994, Beck 1997). Evaluation of habitat (shelter) bottlenecks is particularly important because conservation and resourcemanagement efforts commonly use habitat size as a surrogate measure for population size. In fact, the idea of habitat bottlenecks has led to the use of artificial habitats as a management tool to increase population sizes, especially in marine systems (e.g. Bohnsack 1989). However, conserving or managing the habitat for one life history stage may or may not increase population size, depending on the presence and intensity of a habitat bottleneck (Beck et al. 2001, B. S. Halpern et al. unpubl.).

Several possible scenarios exist for how habitat bottlenecks for stage-structured species can occur and interact. Since adults reproduce to sustain a popula- 
tion, it is ultimately the adult population size that matters, and so habitat bottlenecks need to be assessed for their impact on adults. Adult population size could be limited by a bottleneck at a single stage, with no evidence of limitation at any other stage, as would be the case for species that are strongly recruitment-limited. Adult population size could also ultimately be limited by a bottleneck at a single stage, even though the available habitat at other life stages appears to be in short supply. In this case, experimental manipulations of habitat availability at each stage would show a response by individuals at that stage, but the ultimate (adult) population size would be dependent on the habitat availability at only one particular stage. Finally, adult population size could be a function of the habitat availability at multiple stages. Distinguishing between these scenarios requires that population size be measured at all stages, but especially the adult stage, when evaluating the ultimate effect on population size of a habitat bottleneck at any particular stage. Furthermore, because adult populations are typically the cumulative result of many recruitment events, the effect of juvenile habitat limitation on subsequent adult population size may not be straightforward.

Studies that have examined juvenile habitat limitation have focused almost exclusively on juvenile population size and distribution (reviewed in Orth et al. 1984, Heck et al. 1997, Minello 1999, Beck et al. 2001). Results from studies that evaluate only one life stage may lead to spurious conclusions about where stagespecific bottlenecks actually occur, as illustrated by the scenarios described above. The few studies that have examined the effects of the availability of juvenile habitat on adult population size have produced variable results, including evidence for limitation (Wahle \& Steneck 1991), no limitation (Beck 1995), and mixed results depending on the species (Holbrook et al. 1990).

A major challenge in evaluating how juvenile habitat availability affects adult population size is finding feasible ways to manipulate the amount of juvenile habitat. For example, it is difficult to alter experimentally the amount of nursery habitat (such as seagrass beds or mangroves) for a marine species at a scale large enough to have a detectable effect on adult population size. There are at least 3 reasons why hermit crabs offer a tractable experimental system for testing the impact of juvenile habitat bottlenecks on adult population size. First, it is very easy to alter habitat availability. Hermit crabs must have an empty snail shell to use as a home (with rare exceptions, such as when they use tubeworm casings as a home), and so manipulations of shell availability result in changes in available habitat for the hermit crabs. Second, hermit crabs are very selective in their choice and use of shells and will constantly change shells to find the size and type of shell that best fits them (i.e. not too big or too small; reviewed in Hazlett 1981). Thus, small crabs are never found in large shells, or large crabs in small shells, making it possible to manipulate the availability of shells in specific size classes to effectively create size-specific habitat bottlenecks. Finally, there is extensive research suggesting that hermit crab populations are limited by shell availability, i.e. that a habitat bottleneck exists (e.g. Vance 1972, Kellogg 1976, Bertness 1981). Manipulations of shell (habitat) availability should therefore elucidate the degree to which juvenile versus adult shell availability acts as a bottleneck for population size, both specifically for hermit crabs and more generally for any species that uses different habitats or resources at different life stages.

Interestingly, nearly all evidence for shell availability as a limiting factor for hermit crab populations focuses on adult shell availability and is based on correlative or suggestive evidence (e.g. Provenzano 1960, Fotheringham 1976a, Shih \& Mok 2000). In fact, the assumption of shell limitation for hermit crab populations has only been tested experimentally twice (Vance 1972, Asakura 1991). In both cases, hermit crab population size increased when shells were added to the system, but in each study only 1 site was investigated using only a single replicate. Hermit crab populations at some sites may not be shelllimited, so it is important to determine where and why populations are shell-limited, and whether it is the juvenile-sized shells, adult-sized shells, or both that are creating a bottleneck for the population.

This research project addressed 2 key questions about hermit crab populations and habitat bottlenecks. First, using hermit crabs as a model system, I experimentally tested if habitat availability limits population size, paying particular attention to whether the availability of juvenile habitat affects adult population size. Answers to this question are important for understanding how populations are limited by different resources at different life stages, and this information can help guide conservation and resource management efforts aimed at managing species that use distinct juvenile habitats. Second, by experimentally manipulating shell availability for both juvenile and adult crabs, I directly tested whether the shell-limitation paradigm for hermit crabs is valid at spatial and temporal extents beyond those previously attempted.

\section{MATERIALS AND METHODS}

Study species. This study focused on 2 species of intertidal hermit crabs present in central California, Pagurus samuelis and P. hirsuitisculus. Both species use almost exclusively shells of the snails Littorina spp. 
and Tegula funebralis as their homes (shells $>4 \mathrm{~mm}$ : $99.9 \%$ of the shells used by hermit crabs in this study), but use shells from Lacuna spp. when they first settle in the intertidal (shells $<4 \mathrm{~mm}$ ). Recruitment of these hermit crabs varies spatially across central California (S. Gaines \& C. Blanchette unpubl.) and typically begins in March and ends in August, although some sites receive recruits until November (Worcester \& Gaines 1997). Evidence of growth rates from congeneric species of hermit crabs shows that adult hermit crabs can grow 0.3 to $1.0 \mathrm{~mm} \mathrm{mo}^{-1}$ (Bertness 1981) and that some species can reach maturity within 4 mo and maximum adult size within 8 mo (Fotheringham 1976b). Juvenile hermit crabs have been shown to grow $0.4 \mathrm{mg} \mathrm{d}^{-1}$ (Angel 2000). For the species studied here, I tested their growth rates in replicated aquaria over $18 \mathrm{wk}$, when food was abundant, predators were absent, and small shells varied in abundance from scarce to abundant. New recruits grew large enough to occupy large juvenile shells (11 to $14 \mathrm{~mm}$ along the longest axis) in 2 to $3 \mathrm{mo}$, and over $50 \%$ of the crabs had grown large enough to fill adult shells (14 to $20 \mathrm{~mm}$ ) by the end of the experiment $(3.5 \mathrm{mo})$, regardless of the availability of small shells. Consequently, recruits that settled into tide pools in March or April could grow large enough to occupy small juvenile shells within a month or two, and large enough to occupy adult-sized shells by June or July, assuming growth rates are equivalent in the field (see 'Results').

Experimental design. Experimental manipulations of shell availability were conducted at 9 sites along the central California coast (Fig. 1) in May to October 2002. Sites were chosen to be as similar as possible; all had gently sloping rocky intertidal areas large enough to provide adequate replication for the treatments, were well protected from wave action (except Hazards, which was moderately exposed), and had an abundance of tide pools. Tide pools were chosen to be $0.6 \mathrm{~m}$ above meanlow-low (MLL) tide height and no greater than $2 \mathrm{~m}$ in length. Each pool was measured for pool depth (deepest point) and elliptical surface area (the average of 2 ellipses calculated from N-S and E-W axes and NE-SW and NW-SE axes). Pool volume was calculated as half the volume of the average ellipsoid (calculated from depth and surface-area measurements). To allow for independent samples, pools were selected at least $10 \mathrm{~m}$ apart from each other. Previous studies on intertidal hermit crab movement suggest that individual crabs generally restrict their movement to an area no greater than about 10 to $15 \mathrm{~m}$ in diameter (Hazlett 1981, 1983). Although it is possible that individual hermit crabs moved between treatment pools, it is highly unlikely since 10 to $15 \mathrm{~m}$ is a maximum (not average) distance that these hermit crabs are thought to move, i.e. dispersal events of this distance were probably rare at most.

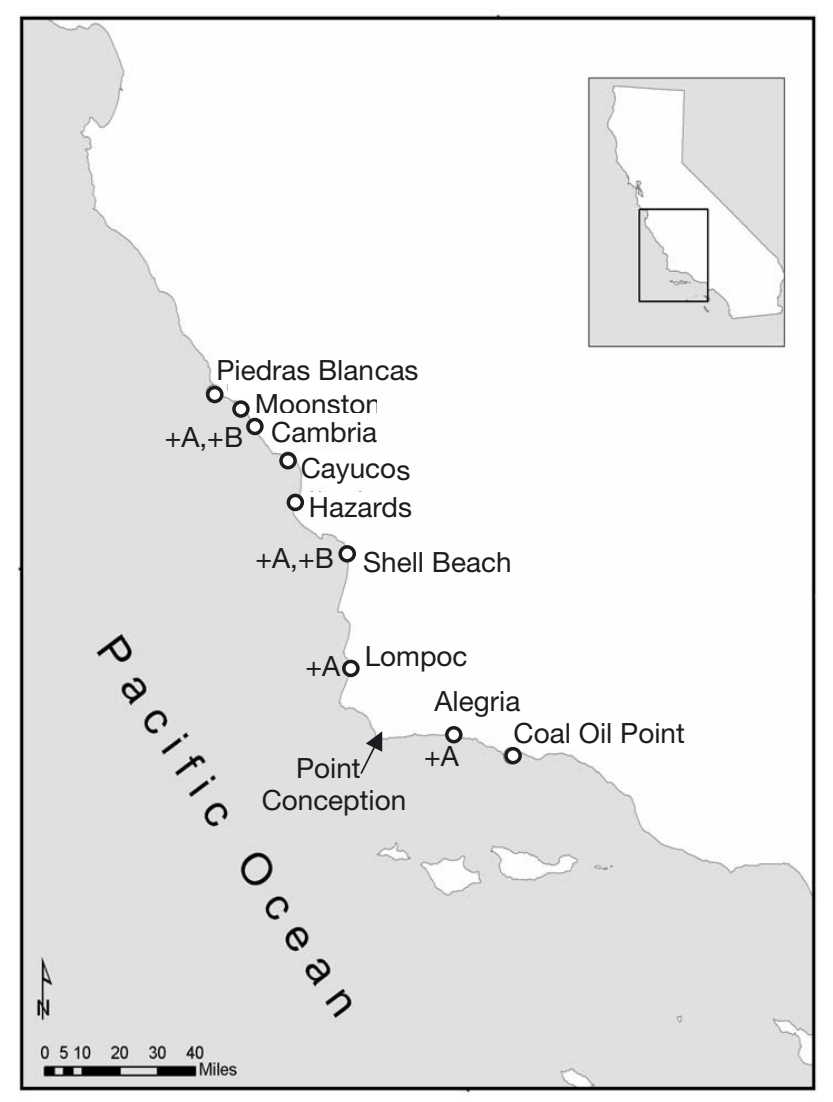

Fig. 1. Map of 9 sites in Central California where experiments were conducted. All sites had control pools and juvenile shelladdition treatments; + A sites also had pools which received adult shells, and $+\mathrm{B}$ sites pools to which both juvenile- and adult-size shells had been added

At each site, 3 replicates were established of control pools and pools in which an excess of juvenile-sized shells were added (see below for shell size classes). An excess of empty shells was defined as a minimum of $25 \%$ empty shells of each size class present in a pool during the prior week. Most added shells were Littorina spp., although some were small Tegula funebralis. Empty shells were tethered with 15 to $25 \mathrm{~cm}$ of $6.8 \mathrm{~kg}$ (15 lb) test nylon fishing line to an eye-bolt sunk into the center of each tide pool. Pilot studies had suggested that tethering did not significantly decrease the desirability of the empty shells; in an aquarium, hermit crabs quickly moved into tethered shells (within seconds in many cases) and remained in those shells for up to $3 \mathrm{wk}$, despite no food being available and the presence of other empty, untethered shells in the tank.

At 4 of the 9 sites, adult-sized shells were added to 3 additional replicate pools (see below for shell size classes; ' $+\mathrm{A}^{\prime}$ sites in Fig. 1). Adult-sized shells were exclusively Tegula funebralis shells. This additional 
treatment tested for adult habitat bottlenecks, but was not included at all sites because of limited space on many of the rocky intertidal benches. Finally, the intertidal benches at Shell Beach and Cambria were large enough to allow inclusion of 3 replicates of a treatment, whereby shells of both sizes were added to the same pool ('+B' sites in Fig. 1). This treatment was included to help evaluate the relative effect of juvenile and adult habitat bottlenecks on adult population size. Unfortunately, sample size for this final treatment turned out to be too small to overcome the variability inherent in the system.

Shells added to tide pools were divided into 4 size classes, measured along the longest axis of the shell: 2 juvenile size classes ( 8 to $11 \mathrm{~mm}$ and 11 to $14 \mathrm{~mm}$ ) and 2 adult size classes (16 to $19 \mathrm{~mm}$ and 19 to $22 \mathrm{~mm}$ ). These shell size classes were determined by the size of the openings in available mesh sifters and so do not represent a clean division between use by juvenile and adult crabs; the juvenile and adult labels are used only for convenience. It was not possible to tether shells smaller than $8 \mathrm{~mm}$, so very small shells were not added to pools. However, hermit crabs in these small shells were counted during surveys and divided into 3 additional shell size classes: $<1 \mathrm{~mm}$ (new recruits that had not developed full coloration and therefore had probably settled out of the plankton within the course of the previous week), 1 to $4.5 \mathrm{~mm}$, and 4.5 to $8 \mathrm{~mm}$.

Before experimental treatments were established, each pool was surveyed to count the number of snails, hermit crabs, and empty snail shells in each shell size class except recruits (April 2002). Treatments were then established. Pools at Coal Oil Point, Alegria, Lompoc and Piedras Blancas received 5 empty shells for each appropriate size class, while the other 5 sites received 10 shells per appropriate size class. Different numbers of shells were added to each pool because fewer shells were needed at some sites to fulfil treatment conditions (an excess of empty shells); larger hermit crab populations were likely to need more shells. Every week each pool was monitored to (1) release any hermit crabs that had moved into the tethered shells (i.e. the tether was cut) and (2) add more empty tethered shells to maintain an excess of empty shells of the appropriate size class in each addition pool. Rarely were more that $50 \%$ of any size class of added shells occupied by hermit crabs at the end of each week, and never were more than $75 \%$ occupied.

Once a month for 3 mo after treatments were established (May to July), all tide pools (controls and treatments) were surveyed to count the number of hermit crabs in all 7 shell size classes (recruits through large adults). Individuals were sifted through mesh with different size openings $(4.5,8,11,14,16,19$ and $22 \mathrm{~mm})$ to separate individuals into size classes. Hermit crabs that had colonized tethered shells over the previous week were included in survey counts. At the end of the third month (July 2002), 40 to 60 empty, tethered shells (10 to 20 in each size class, depending on past patterns of shell occupation) were added to each shell-addition pool to sustain experimental treatments for an extended period of time. Pools were then checked for a final time at the end of the sixth month (October 2002). Individual crabs were likely to have moved into and out of these tethered shells during the course of the $3 \mathrm{mo}$, so that no single crab occupied a shell for the entire time but that availability of empty shells was probably maintained (there were $>25 \%$ empty shells in each size class on the final survey date). Hermit crab recruitment had stopped by this time, so no recruits were present during the final survey.

Data for both species of hermit crabs were combined for all analyses. This was done primarily because recruits and small individuals (smallest shell size class) had not developed the defining coloration of the species, so that it was not possible to distinguish between the species at these stages. Initial population sizes (adjusted for pool volume) for the species were not significantly different at any site or between treatment pools at a site, except for a marginal within-site difference at Cambria (ANOVA; df $=1, F=4.47, \mathrm{p}=0.04$ ) and within-treatment and within-site differences at Cayucos (ANOVA; within-treatment: $\mathrm{df}=1, F=8.58$, $\mathrm{p}=0.005$; within-site: $\mathrm{df}=1, F=9.60, \mathrm{p}=0.003$ ). Therefore, this lumping of species data probably did not affect the results.

Statistical analyses. I used repeated-measures multivariate analysis of variance (MANOVA) to test the effects of shell-addition treatments and site (independent variables) on hermit crab population sizes across time (dependent variables; Von Ende 1993). This method allows one to test if the treatments affect population sizes relative to the control over time (levels), if population sizes change over time regardless of treatment (flatness), and if population sizes in control and treatment tide pools change in the same direction and rate over time (parallelism). Furthermore, MANOVA tests account for adjustments to significance levels when multiple tests are performed, which require Bonfferoni or other corrections in separate univariate tests.

Each MANOVA was performed using the size of the total, juvenile, or adult hermit crab populations separately as the dependent variables. Prior to MANOVAs, data (values +0.5 ) were square-root-transformed to normalize their distribution, account for 0 data values, and adjust for mean-variance scaling in abundance data (Zar 1996). At Shell Beach in July, due to a rare aggregation event (perhaps for reproduction) 1 adultshell-addition pool had an order of magnitude higher 
number of hermit crabs than any other pool at any other site throughout the entire experiment. This anomalously high datum was removed from all analyses. Furthermore, a few pools were occasionally buried in sand at some sites, and so data were not available for those pools at those times. In particular, 1 juvenile shell-addition pool was buried in June and July at Coal Oil Point and 2 were buried in October; 1 control pool was buried in October at Coal Oil Point and Cayucos; and 1 adult shell-addition pool was buried in July and 2 in October at Alegria. These differences between sites in final number of replicates may have affected the results of site comparisons (although these were highly significant; see 'Results'), but were unlikely to have affected treatment comparisons since the MANOVA test aggregates all replicates across sites to test for treatment effects.

Contrast tests (Helmert routine) were used to compare each pair of time intervals to evaluate when significant changes occurred in treatment and control pools. I used 2-way ANOVA and correlation analyses to test for relationships between sites in their response to experimental treatment and for correlations between site attributes.

\section{RESULTS}

\section{Initial conditions}

Tide pools were $13.1 \pm 0.8 \mathrm{~cm}$ deep (mean $\pm \mathrm{SE}_{\text {; }}$ range: 3 to $35 \mathrm{~cm}$ ) and $0.49 \pm 0.06 \mathrm{~m}^{2}$ in surface area (mean \pm $\mathrm{SE}_{\text {; }}$ range: 0.03 to $2.61 \mathrm{~m}^{2}$ ). There were no significant differences in pool depth, area, or volume between treatments, but significant differences did exist between sites for pool surface area and pool volume (Table 1). Multiple-range tests (Tukey-Kramer) indicated that Lompoc pools had significantly larger surface areas than those at most other sites and that Alegria had significantly larger pool volumes than Cambria. All other pairwise comparisons were not significantly different.

Initial numbers of hermit crabs and snails differed across sites, but the number of empty shells did not (Table 2, Fig. 2). Generally, the northern sites had much larger populations of snails and hermit crabs than the southern sites (Fig. 2); this pattern was not reflected in the number of empty shells at each site (Table 2). There were no significant differences in the initial numbers of hermit crabs, snails or empty shells between control and treatment pools, except for differences in the number of snails when comparing juvenile-sized shell-addition pools to control pools (+ J vs C: Table 2). Therefore, differences in hermit crab numbers between control and treatment pools after treatments were established can be attributed to a treatment effect and not to inherent differences between pools.

Initial conditions can also be used to infer processes that occurred in the past. For example, correlations between initial snail population size and initial numbers of either hermit crabs or empty snail shells may indicate that these variables are affected by the potential input of shells from live snails. At the site level, where values from all pools at a site are averaged, the initial population size of the hermit crabs was correlated with the initial population size of the snails ( $p=$ $0.014, r=0.88)$, but empty shell availability was not

Table 1. Results of 2-way ANOVA testing for differences in tide-pool features between different sites and treatments. Data are from 9 sites and 4 different treatments (see 'Materials and methods'). Pool area and volume were calculated as ellipses and half ellipsoids. p-values significant at 0.05 level indicated in bold

\begin{tabular}{|c|c|c|c|c|c|c|c|}
\hline \multirow[t]{2}{*}{ Source } & \multirow[t]{2}{*}{ df } & \multicolumn{2}{|c|}{ Pool depth } & \multicolumn{2}{|c|}{ Pool area } & \multicolumn{2}{|c|}{ Pool volume } \\
\hline & & $F$ & $\mathrm{p}$ & $F$ & $\mathrm{p}$ & $F$ & $\mathrm{p}$ \\
\hline Site $(\mathrm{S})$ & 8 & 2.7219 & 0.1055 & 6.7429 & 0.0125 & 4.391 & 0.0414 \\
\hline Treatment $(\mathrm{T})$ & 3 & 0.0211 & 0.8851 & 1.2114 & 0.2765 & 0.1064 & 0.7457 \\
\hline $\mathrm{S} \times \mathrm{T}$ & 24 & 1.0004 & 0.463 & 0.765 & 0.682 & 1.0921 & 0.388 \\
\hline
\end{tabular}

Table 2. Results of 2-way ANOVAs for differences in initial conditions between treatment and control pools and among sites for number of hermit crabs (Pagurus ssp.), snails (Littorina sp. and Tegula funebralis) and available empty shells. Separate tests compared juvenile-shell-addition pools $(+\mathrm{J})$ to control pools $(\mathrm{C})$; adult-shell-addition pools $(+\mathrm{A})$ to both $+\mathrm{J}$ and $\mathrm{C}$ pools; and pools with both sizes of shells added $(+B)$ to $+\mathrm{J},+\mathrm{A}$ and $\mathrm{C}$ pools. Significant effects $(p<0.05)$ indicated in bold

\begin{tabular}{|c|c|c|c|c|c|c|c|}
\hline \multirow[t]{2}{*}{ Source } & \multirow[t]{2}{*}{$\mathrm{df}$} & \multicolumn{2}{|c|}{ Hermit crabs } & \multicolumn{2}{|c|}{ Snails } & \multicolumn{2}{|c|}{ Empty shells } \\
\hline & & $F$ & $\mathrm{p}$ & $F$ & $\mathrm{p}$ & $F$ & $\mathrm{p}$ \\
\hline \multicolumn{8}{|l|}{$+\mathrm{J}$ vs $\mathrm{C}$} \\
\hline Site (S) & 8 & 2.644 & 0.022 & 4.552 & 0.0007 & 0.883 & 0.54 \\
\hline Treatment $(\mathrm{T})$ & 1 & 0.757 & 0.39 & 7.108 & 0.011 & 3.511 & 0.069 \\
\hline $\mathrm{S} \times \mathrm{T}$ & 8 & 0.245 & 0.979 & 1.211 & 0.321 & 0.727 & 0.667 \\
\hline \multicolumn{8}{|l|}{$+\mathrm{J}$ vs $+\mathrm{A}$ vs $\mathrm{C}$} \\
\hline Site (S) & 3 & 6.558 & 0.002 & 5.828 & 0.004 & 2.864 & 0.058 \\
\hline Treatment (T) & 2 & 0.611 & 0.551 & 2.289 & 0.123 & 2.004 & 0.157 \\
\hline $\mathrm{S} \times \mathrm{T}$ & 6 & 0.209 & 0.971 & 1.3 & 0.295 & 0.572 & 0.749 \\
\hline \multicolumn{8}{|c|}{$+\mathrm{J}$ vs $+\mathrm{A}$ vs $+\mathrm{B}$ vs $\mathrm{C}$} \\
\hline Site $(\mathrm{S})$ & 1 & 2.045 & 0.172 & 5.099 & 0.038 & 0.836 & 0.374 \\
\hline Treatment $(\mathrm{T})$ & 3 & 2.232 & 0.124 & 2.604 & 0.088 & 1.168 & 0.353 \\
\hline $\mathrm{S} \times \mathrm{T}$ & 3 & 0.375 & 0.772 & 1.263 & 0.321 & 0.821 & 0.501 \\
\hline
\end{tabular}




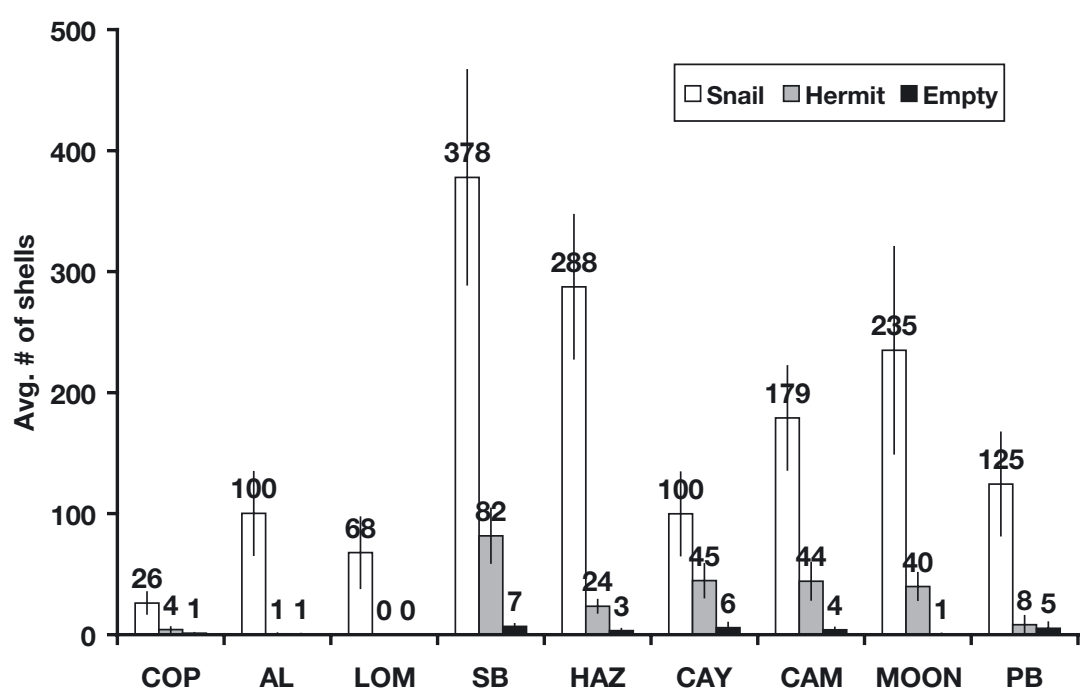

Fig. 2. Initial conditions. Average numbers of hermit crabs (Pagurus spp.) and empty snail shells (Littorina spp. and Tegula funebralis) per pool at each site before experimental manipulations were established (April 2002). Bars are mean \pm 1 SE per pool for all pools (treatments and control) at a site; actual values are indicated above each bar. Sites are arranged left to right (from south to north in Fig. 1). COP: Coal Oil Point; AL: Alegria; LOM: Lompoc; SB: Shell Beach; HAZ: Hazards; CAY: Cayucos; CAM: Cambria; MOON: Moonstone; PB: Piedras Blancas

$(\mathrm{p}=0.20, \mathrm{r}=0.82)$. Initial sizes of the hermit crab populations were also correlated with empty shell availability at the site level $(p=0.047, r=0.67)$, even though empty shell availability did not vary significantly across sites. To determine if site-level patterns were viable at the tide-pool level, I converted all population sizes to densities (to adjust for pool volume) and looked for correlations between factors. These comparisons also showed that initial numbers of hermit crabs (of all sizes) were significantly correlated with initial snail abundance within tide pools (correlation analysis: $\mathrm{p}<0.0001, \mathrm{r}=0.69$ ), although the number of empty shells was not (correlation analysis: $p=0.069, r=0.22$ ).

\section{Population responses}

The addition of empty juvenile shells had a significant effect on the total population size of the hermit crabs (abundance per pool of all hermit crab sizes except recruits) when data from all sites were combined (see Table 3). This result was probably driven by the highly significant response of juvenile-sized hermit crabs to this shell-addition treatment (Table 3, Fig. 3A), as adult hermit crab populations were not affected by the addition of empty juvenile-sized shells (Table 3, Fig. 3C). Adult hermit crab populations were also not significantly affected by adult shell-additions (Table 3), although there was a positive trend in popu- lation size (Fig. 3C). These patterns of response to shell-additions were not evident in the pools where both sizes of shells were added (repeated-measures MANOVA, juvenile hermit crab response: $\mathrm{df}=1,5, F=2.02, \mathrm{p}=0.19$; adult hermit crab response: $\mathrm{df}=1,5, F=$ $0.96, p=0.36 ; p>0.19$ for all other effect tests and interactions), however the sample size was very small for these treatments relative to the amount of variability in hermit crab numbers (SD roughly equal to the mean for most months and among all months).

Total, juvenile and adult hermit crab population sizes varied significantly among sites (site effect in Table 3). This suggests that the underlying population sizes of hermit crabs at the various experimental sites are different, regardless of treatment (this test combined control and treatment pools to test for site effects). This result is consistent with the results of analyses of initial conditions at the sites (see preceding subsection). Interestingly, these site differences did not affect the magnitude of the treatment effect $(\mathrm{T} \times \mathrm{S}$ effects in Table 3$)$.

There is also evidence of recruitment limitation in total population size of these hermit crab species. Average hermit crab population size (excluding recruits) at each site, both pre-treatment (April) and across all times (April through October), was strongly correlated with the average recruitment level of hermit crabs (May through July) at each site (Fig. 4; correlation analysis, April only: $\mathrm{p}=0.002, \mathrm{r}=0.87$; all times: $\mathrm{p}=$ $0.003, r=0.87$ ). These results confirm recruitment patterns seen by S. D. Gaines and C. A. Blanchette (unpubl. data), suggesting that this limitation is most severe around and south of Point Conception. Similarly, population sizes of adult-sized hermit crabs were correlated with recruitment patterns (correlation analysis, April only: $\mathrm{p}=0.076, \mathrm{r}=0.62$; all times: $\mathrm{p}=0.046, \mathrm{r}=$ 0.68; Fig. 4), although not as strongly, indicating that patterns of recruitment persist into the adult stage. Interestingly, initial snail abundance also correlated strongly with average hermit crab recruitment rates at each site (correlation analysis, $p=0.005, r=0.84$ ). Since snail and hermit crab population abundance were correlated across sites (see 'Initial conditions' above), this result suggests that snails and hermit crabs recruited in similar patterns across the experimental sites. This has important consequences for interpreting the presence and strength of potential bottlenecks in this system, an issue examined in detail in the 'Discussion'. 
Table 3. Results of MANOVA tests of response of different size classes of hermit crabs to juvenile-sized (Juv) and adult-sized (Adult) shell-additions. Analyses are of post-treatment data (May to October). Treatment (T) effects test for differences in 'levels', month $(\mathrm{M})$ effects test for flatness of data, and treatment by month $(\mathrm{T} \times \mathrm{M})$ effects test for parallelism between treatment and control pools over time. $F$ - and p-values for $\mathrm{M} \times \mathrm{S}, \mathrm{T} \times \mathrm{M}$, and $\mathrm{T} \times \mathrm{S} \times \mathrm{M}$ interactions calculated by Pillai's trace. $\mathrm{p}$-values significant at 0.05 level indicated in boldface. Shells used were from Littorina spp. and Tegula funebralis

\begin{tabular}{|c|c|c|c|c|c|c|c|c|c|c|}
\hline \multirow[t]{2}{*}{ Source } & \multirow[b]{2}{*}{ df } & \multicolumn{4}{|c|}{ Juvenile-sized shell-additions } & & & \multicolumn{3}{|c|}{ Adult-sized shell-additions } \\
\hline & & $F$ & $\mathrm{dV}-\frac{}{\mathrm{p}}$ & $\bar{F}$ & dult $\overline{\mathrm{p}}$ & $\bar{F}$ & $\operatorname{tal}$ & df & $\bar{F}^{A}$ & $\bar{p}$ \\
\hline Treatment $(\mathrm{T})$ & 1,31 & 9.967 & 0.004 & 0.329 & 0.570 & 4.296 & 0.047 & 1,14 & 1.812 & 0.200 \\
\hline Site $(\mathrm{S})$ & 8,31 & 5.500 & $<0.001$ & 7.214 & $<0.001$ & 6.150 & $<0.001$ & 3,14 & 6.544 & 0.005 \\
\hline Month (M) & 3,29 & 2.026 & 0.132 & 4.024 & 0.017 & 5.502 & 0.004 & 3,12 & 2.410 & 0.118 \\
\hline $\mathrm{T} \times \mathrm{S}$ & 8,31 & 0.653 & 0.728 & 0.225 & 0.984 & 0.479 & 0.861 & 3,14 & 0.460 & 0.715 \\
\hline $\mathrm{T} \times \mathrm{M}$ & 3,29 & 0.858 & 0.474 & 0.691 & 0.565 & 0.456 & 0.715 & 3,12 & 0.820 & 0.507 \\
\hline $\mathrm{M} \times \mathrm{S}$ & 24,93 & 1.290 & 0.193 & 1.490 & 0.091 & 1.306 & 0.183 & 9,42 & 1.414 & 0.213 \\
\hline $\mathrm{T} \times \mathrm{S} \times \mathrm{M}$ & 24,93 & 0.956 & 0.530 & 1.155 & 0.305 & 1.192 & 0.270 & 9,42 & 0.886 & 0.546 \\
\hline
\end{tabular}
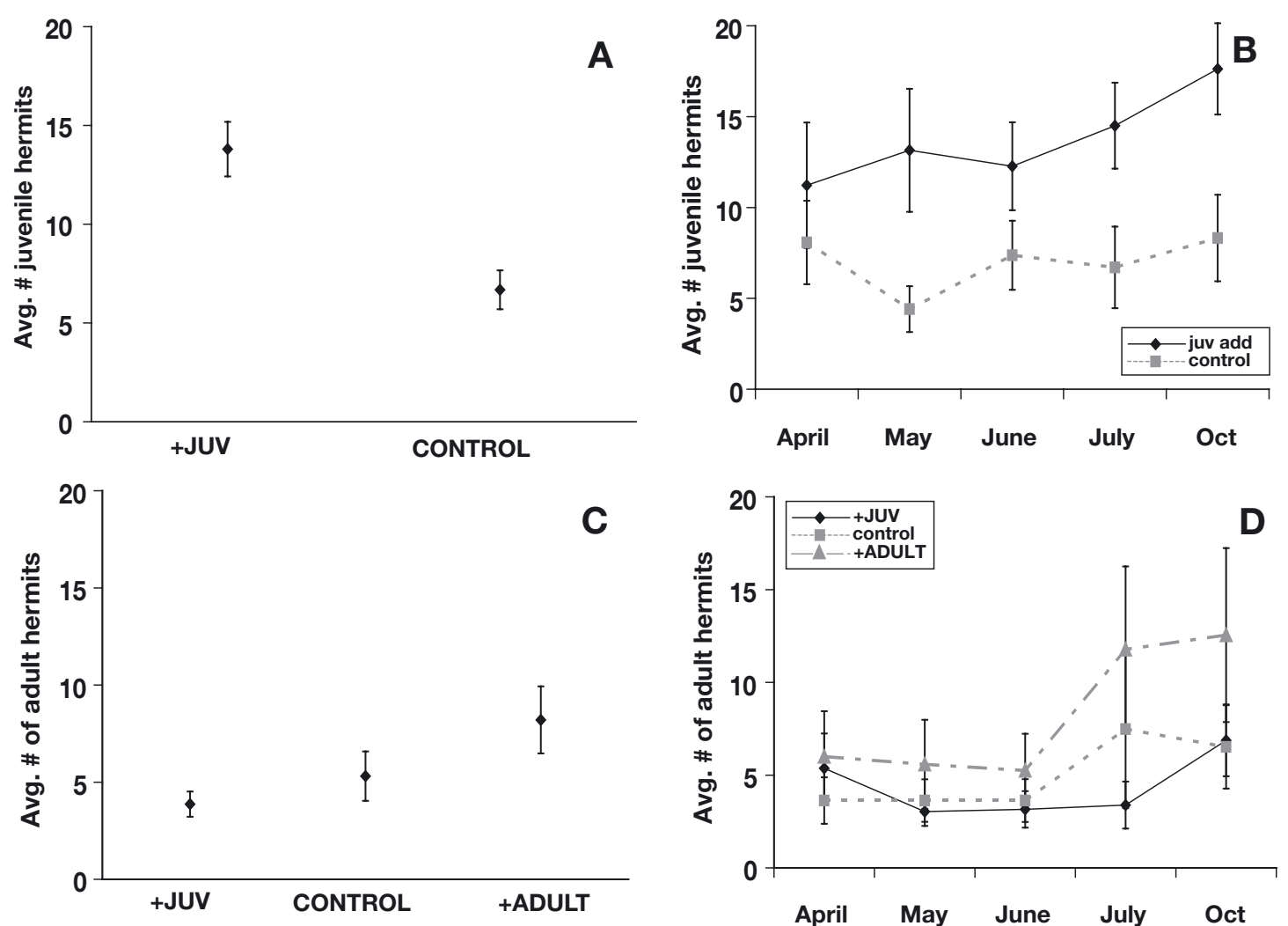

Fig. 3. Pagurus spp. (P. samuelis and P. hirsuitisculus) average abundance per pool of juvenile-sized and adult-sized hermit crabs for each experimental treatment. Data points are grand mean values across all 9 sites, $\pm 1 \mathrm{SE}$, with those in (A) and (C) averaged across all months of experiment (May to October 2002), and those in (B) and (D) mean values for each month. (A,B) population responses of juvenile-sized hermit crabs to addition of juvenile-sized shells; $(C, D)$ population responses of adult-sized hermit crabs to additions of both juvenile-size and adult-size shells

\section{Temporal effects}

Total and adult-sized hermit crab population sizes in the combined control and juvenile shell-addition pools increased significantly across months, while juvenilesized hermit crabs did not (Table 3). Despite significant responses by juvenile-sized hermit crabs to juvenile shell-additions (levels effect), in no case were the responses of hermit crabs to shell-additions over time significantly different from responses in control pools $(\mathrm{T} \times \mathrm{M}$ effect in Table 3; see also Fig. 3B,D). Furthermore, contrast analyses comparing all pairs of months for each size class of hermit crabs (total, adults, juveniles) for each treatment (juvenile-sized and adult- 
sized shell-additions) also showed no significant differences, suggesting that the treatment effect ('levels') for juvenile-sized hermit crabs in juvenile-sized shelladditions pools accumulated quickly (April to May) and then persisted over time (Fig. 3B).

Average recruitment was highest in July at most sites (Fig. 5), but had ended at all sites by October. Given the hermit crab growth rates discussed at the beginning of 'Materials and methods', these July recruits were likely to have grown to juvenile size, but not yet to adult size, by the end of the experiment.

\section{DISCUSSION}

For the intertidal hermit crabs studied here, the results suggest that adult hermit crab populations are potentially limited by the amount of adult habitat, but not by the amount of juvenile habitat. Although the response by adult crabs to the addition of adult-sized shells was not statistically significant, there was a positive trend in the response (Fig. 3C). Furthermore, overall adult-sized hermit crab numbers increased significantly in the last 3 mo of the experiment (Fig. 3D), and late-summer recruits had probably not yet grown to adult size, indicating that the adult hermit crab population may become large enough to create a significant habitat bottleneck later in the year. Conversely,

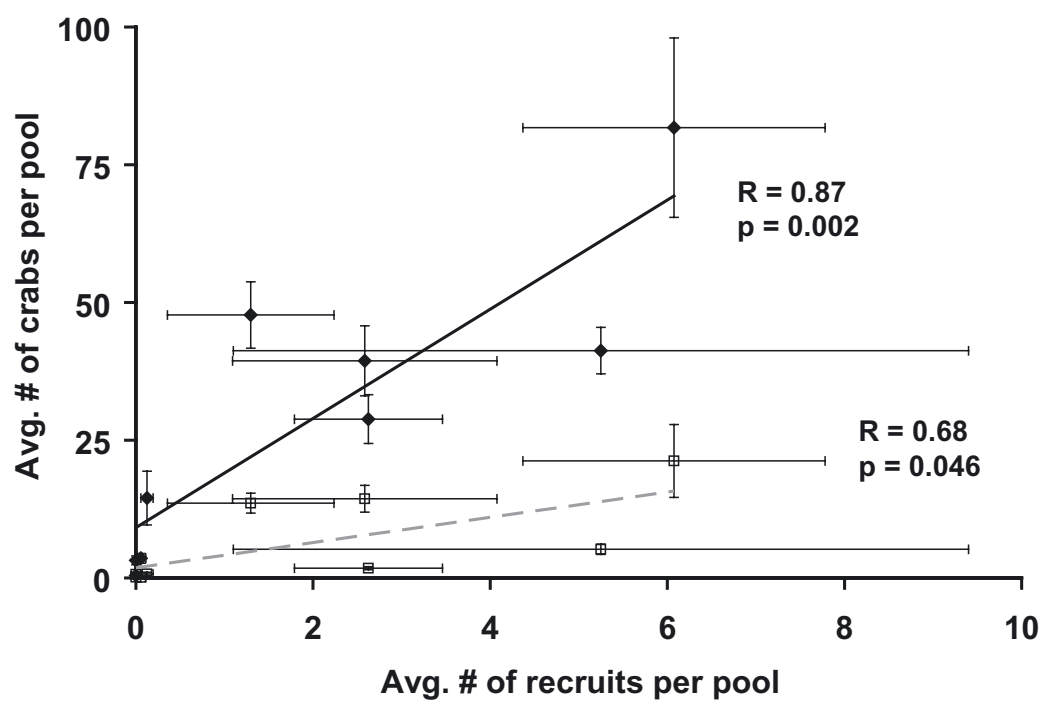

Fig. 4. Pagurus spp. Total hermit crab abundance excluding recruits $(\bullet)$ and adult sizes only ( $\square$ ) versus average hermit crab recruitment at each site. Data points are average values per site $( \pm 1 \mathrm{SE})$ for each variable across all pools and times at each site. Hermit crab population sizes were averaged across 5 mo (April to October 2002). Recruitment rates were averaged over the 3 mo recruitment measurements (May to July 2002). Correlations are: continuous line (values in upper right corner) = total population size; dashed line (values in lower right corner) = adult sizes only there was a highly significant response by juvenilesized hermit crabs to the addition of juvenile-sized shells (Fig. 3A), but no significant response by adultsized hermit crabs to this treatment (Fig. 3C), indicating that the availability of juvenile-sized shells has little effect on the ultimate adult population size even though it has strong consequences for juvenile-sized hermit crabs.

These results suggest a seasonality to the habitat bottlenecks that hermit crabs experience, as well as to their population size. In the spring, adult-sized hermit crab populations were not large enough to experience a habitat bottleneck, as demonstrated by the lack of initial response to the addition of large shells in this experiment, but juvenile hermit crabs did experience a brief bottleneck in juvenile shell availability. Juvenile population size then remained constant (Fig. 3B; non-significant $\mathrm{T} \times$ $M$ effect in Table 3), despite increases in recruitment rates over time, suggesting that individuals were growing out of the juvenile population at the same rate that recruits were growing into it. By late summer, a sufficient number of these juveniles had grown to the adult stage to create a (non-significant) adult habitat bottleneck. It is important to note that the increases in adult numbers in July and October must have arisen from recruits earlier in the year, since hermit crabs do not spend more than a few months as juveniles. In other words, early-season recruits (March/April) had grown to adult size in 3 to 4 mo (July). The experiment ran twice as long as this, so that significant responses by adult hermit crabs to juvenile shell-additions should have been detectable during the experiment. In fact, the increase in the number of adult hermit crabs in October in the juvenile shelladdition pools (Fig. 3D) may reflect an initial response to the high recruitment in July (Fig. 5). If so, then juvenile shell availability may limit adult population size when recruitment is very high.

Although the limited availability of juvenile-sized shells may not directly affect adult population size, it could slow the rate at which the full adult population size is reached. Research has demonstrated that hermit crabs can alter their growth rate if shells are too small or too large (Fotheringham 1976b, Bertness 1981, Angel 2000), and so the juvenile hermit crabs in this experiment probably slowed their growth rate in response to the limited availability of juvenile-sized shells. Because the adult habitat bottleneck appears to be seasonal in nature (if it 


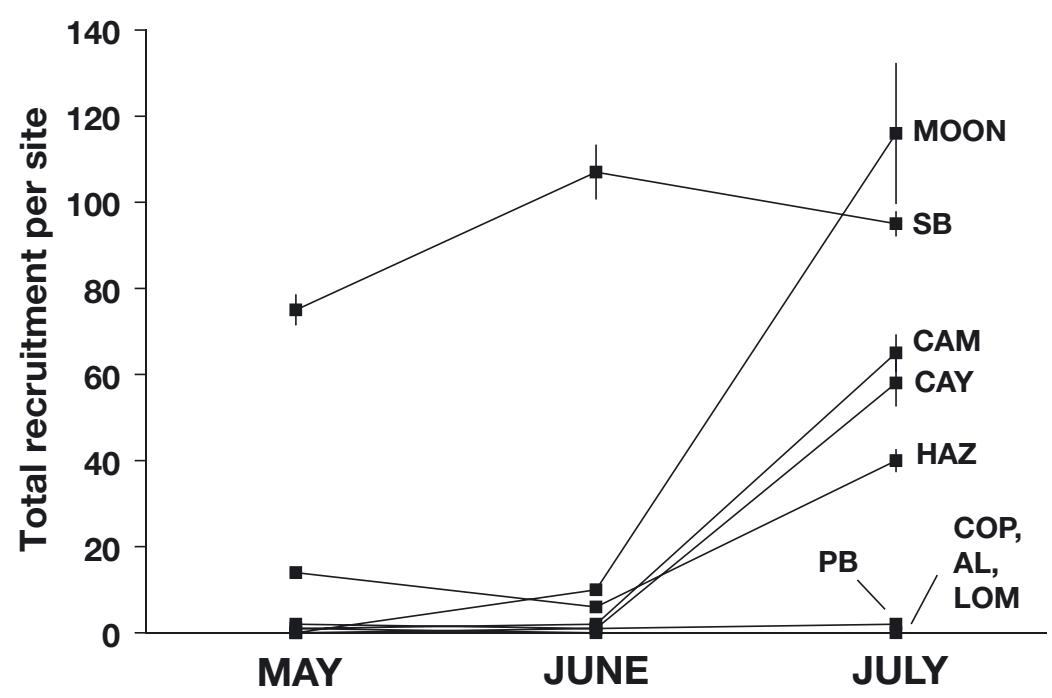

Fig. 5. Pagurus spp. Average total recruitment at each site during each of the 3 mo that recruitment was measured. Values are mean \pm SE for all control and treatment pools at the relevant site (error bars for most points are very small). Sites labeled as in Fig. 2

occurs), then this delay in growth caused by juvenile habitat availability may delay the time it takes for the population size to become large enough to experience the habitat bottleneck. In turn, the later onset of the adult habitat bottleneck may actually decrease its impact on the population size, i.e. the bottleneck would still limit the population size, but other factors such as predation or density-independent mortality might become more important in determining the fate of individual crabs.

Even though the availability of juvenile-sized shells appears to not create a bottleneck for adult populations of hermit crabs, except perhaps when recruitment is high, such a bottleneck may still occur. The addition of juvenile-sized shells could lead to significant increases in juvenile populations and real but undetectable increases in adult population sizes if juvenile and adult hermit crabs have different scales of movement. If juvenile hermit crabs move relatively short distances (e.g. within a single tide pool) and adult hermit crabs move longer distances (e.g. between pools), then shell-additions would lead to detectable increases in juvenile populations within the pool but undetectable increases in adult populations because the scale of the adult population is larger than the experimental unit (i.e. a single tide pool). Furthermore, the strong response by juvenile hermit crabs to juvenile shell-additions indicates that in locations where adult shells are highly abundant, a strong juvenile habitat bottleneck may exist. Evidence from hermit crabs in Madagascar demonstrates that this pattern of resource availability and bottlenecks can occur (Barnes \& De Grave 2002).
The correlation between population size and recruitment (Fig. 4) suggests that recruitment may act as a bottleneck to abundance of the hermit crab population. Consequently, hermit crab numbers may be set by initial numbers of recruits arriving at a site and then modified secondarily by the number of adult-sized shells available. This sequence of bottlenecks would explain why the correlation was weaker with adult-sized hermit crabs than with total hermit crab population size (Fig. 4). However, this correlation may be driven by a different causal relationship. Strong correlations between initial hermit crab and snail population sizes at a site, and between these and hermit crab recruitment, indicate that the snails ultimately providing shells to the hermit crabs may be recruiting in a pattern similar to that of the hermit crabs. If so, hermit crab population size may correlate with hermit crab recruitment rates because the population size is actually limited by hermit crab recruitment rates, or because the population size is limited by the availability of snail shells that happen to recruit to sites in the same pattern as hermit crabs. Distinguishing between these 2 scenarios would require shell-addition experiments at sites with high hermit crab recruitment and small snail population sizes or low hermit crab recruitment and large snail populations; i.e. inferring where a bottleneck occurs from correlations alone may lead to the misidentification of the actual bottleneck. If snail and hermit recruitment rates co-vary at all sites (which is likely), then such sites may not exist. Consequently, it may prove difficult to distinguish in the field between sites where hermit crabs are limited by recruitment alone, adult-sized shell availability alone, or a combination of these 2 factors.

Given the lack of a strong response by hermit crab populations to the addition of adult-sized shells, why were there not more empty shells at sites with more snails? A likely explanation is that wave action may remove empty shells quickly regardless of snail or hermit population sizes. In other words, empty snail shells may enter the system frequently, but wave action removes most of them before they can be seen or counted. Whether or not hermit crabs find the shells before waves remove them would influence the presence and strength of a bottleneck in shell availability for population size.

To determine if wave action could remove shells quickly from the intertidal system, I tested if siliconfilled shells (shells inaccessible to hermit crabs but of a 
similar specific gravity to empty shells) remained in a tide pool at Alegria over a $7 \mathrm{~d}$ period. Even at this site with low wave exposure, all shell size classes were absent from the tide pool (and all pools within a $25 \mathrm{~m}$ radius), except for a few shells that had been colonized by hermit crabs (the crabs had removed the gel plugs). Therefore, empty shells not utilized by hermit crabs can be quickly removed via wave action from tide pools, while those occupied by hermit crabs remain, creating the appearance of extreme shell limitation even though shells may be entering the system frequently and in large numbers.

Hermit crab populations may also be limited by factors such as predation (largely octopi) or food resources that may vary in abundance between sites or pools. These factors were not tested in this study, and so their importance as limiting factors relative to the variables measured here cannot be evaluated. However, such factors would have to vary systematically among sites to counter patterns of response to shell-additions, suggesting that they may not be important for limiting hermit crab population size in the locations studied here.

There are several interesting implications from the results of this work. First, the potential seasonality in the adult-sized habitat bottleneck for hermit crabs suggests that the bottleneck is significant only when the number of adult-sized hermit crabs peaks. Consequently, the habitat bottleneck may not be very strong, since it only occurs when populations are particularly large. Furthermore, this seasonality may confer a reproductive advantage on crabs mating at particular times: if new recruits arrive at a site too early, they will experience a juvenile habitat bottleneck, but if they arrive too late they will eventually encounter the ultimate limiting habitat-bottleneck at the adult stage.

Second, and more importantly, it is critical that efforts aimed at demonstrating population bottlenecks evaluate how a potential bottleneck affects the ultimate adult population size. Measurements of how juvenile populations respond to juvenile habitat availability may lead to spurious conclusions about how an entire population is affected by the availability of that habitat. The results from this experiment illustrate clearly how such a scenario could arise.

A vast literature has developed addressing the sensitivity (or elasticity) of population size to changes in various life history parameters (such as growth rate or mortality; see Caswell 2001 for a review), but these ideas have yet to be applied to issues of habitat bottlenecks. For example, nearly all studies that have evaluated the role of nursery habitats in supporting populations of the species that use these habitats have documented how juvenile populations, but not adult populations, respond to features of the nursery habitat (Beck et al. 2001). It is likely, if not inevitable, that nursery habitats act as a bottleneck for adult population size, but this bottleneck may be released at a very small habitat size. Population models have been developed to evaluate how relative habitat size and recruitment affect the habitat size at which juvenile habitat bottlenecks occur (B. S. Halpern et al. unpubl.).

As mentioned in the 'Introduction', hermit crabs are a particularly useful model system for examining the effects of habitat bottlenecks on population sizes for species with a biogenic habitat. As the factors controlling the dynamics of a species and its habitat become less coupled, however, this model system may prove less useful. For example, recruitment patterns (frequency, intensity, duration) of some reef fishes that use seagrass beds or mangroves as nursery habitats are not likely to be the same as the recruitment patterns of the plants that make up these habitats. If these plants need little recruitment to sustain healthy populations (i.e. vegetative growth could maintain the plant population), then the available juvenile habitat for the fishes would be independent of the recruitment patterns of the fish species. For non-vegetative habitats such as rocky reefs, habitat availability would be completely independent of recruitment patterns; these latter systems may be even more tractable than the hermit crab system because the habitat and species dynamics are not coupled.

Finally, it may be necessary to reconsider the idea that only large-shell limitation exists for hermit crabs. Results from this study show that all 3 stages - recruitment, juvenile and adult stages — can potentially limit hermit crab population size, but that recruitment and adult habitat availability are probably the main limiting factors. These conclusions are in contrast to the long-standing assumption that hermit crabs are mainly limited by the scarcity of large shells.

All these conclusions have implications for conservation and management efforts aimed at species that use distinct juvenile habitats. Such efforts need to focus more attention on both recruitment dynamics and the availability of habitat at all stages of a species' life cycle when developing plans for these species. Early life stages can clearly affect the population size and dynamics of later stages, but these effects may not be straightforward. Efforts that focus only on 1 stage, such as setting up reserves that include only an adult habitat, may prove ineffectual or less effective than those that include multiple life stages. Similarly, habitat restoration efforts may prove ineffectual for helping populations of species that use the habitat if that habitat is not a limiting one. 
Acknowledgements. This work was made possible by funding from an NSF predoctoral fellowship and from the Partnership for Interdisciplinary Studies of Coastal Oceans (PISCO). Thanks to Meghan Faerber for her help with data collection. Bob Warner, Steve Gaines, Scott Cooper, Cathy Pfister, and several anonymous reviewers offered valuable comments on earlier drafts of this manuscript.

\section{LITERATURE CITED}

Angel JE (2000) Effect of shell fit on the biology of the hermit crab Pagurus longicarpus. J Exp Mar Biol Ecol 243: 169-184

Asakura A (1991) Population ecology of the sand-dwelling hermit crab Diogenes nitidimanus. IV. Larval settlement. Mar Ecol Prog Ser 78:139-146

Barnes DKA, De Grave S (2002) Temporospatial constraints in resources available to and used by hermit crabs: tests of models. Funct Ecol 16:714-726

Beck MW (1995) Size-specific shelter limitation in stone crabs: a test of the demographic bottleneck hypothesis. Ecology 76:968-980

Beck MW (1997) A test of the generality of the effects of shelter bottlenecks in four stone crab populations. Ecology 78 : 2487-2503

Beck MW, Heck KL Jr, Able K, Childers D and 9 others (2001) The identification, conservation and management of estuarine and marine nurseries for fish and invertebrates. BioScience 51:633-641

Bertness MD (1981) Pattern and plasticity in tropical hermit crab growth and reproduction. Am Nat 117:754-773

Bohnsack JA (1989) Are high densities of fishes at artificial reefs the result of habitat limitation or behavioral preference? Bull Mar Sci 44:631-645

Caddy JF (1986) Modeling stock-recruitment processes in Crustacea: some practical and theoretical perspectives. Can J Fish Aquat Sci 43:2330-2344

Caswell H (2001) Matrix population models: construction, analysis, and interpretation. Sinauer Associates, Sunderland, MA

DeMartini EE, Roberts DA (1990) Effects of giant kelp (Macrocystis) on the density and abundance of fishes in a cobble-bottom kelp forest. Bull Mar Sci 41:287-300

Fotheringham N (1976a) Hermit crab shells as a limiting resource (Decapoda, Paguridea). Crustaceana 31:193-199

Fotheringham N (1976b) Effects of shell stress on the growth of hermit crabs. J Exp Mar Biol Ecol 23:299-305

Fretwell S (1972) Populations in a seasonal environment. Princeton University Press, Princeton, NJ

Hazlett BA (1981) The behavioral ecology of hermit crabs. Annu Rev Ecol Syst 12:1-22

Hazlett BA (1983) Daily movement in the hermit crabs Clibanarius tricolor and Calcinus tibicen. J Crustac Biol 3: 223-234

Heck KL Jr, Nacleau DA, Thomas R (1997) The nursery role of

Editorial responsibility: Otto Kinne (Editor),

Oldendorf/Luhe, Germany seagrass beds. Gulf Mex Sci 1:50-54

Heck KL Jr, Hays C, Orth RJ (2003) A critical evaluation of the nursery role hypothesis for seagrass meadows. Mar Ecol Prog Ser 253:123-136

Holbrook SJ, Carr MH, Schmitt RJ, Coyer JA (1990) Effect of giant kelp on local abundance of reef fishes: the importance of ontogenetic resource requirements. Bull Mar Sci 47:104-114

Kellogg CW (1976) Gastropod shells: a potentially limiting resource for hermit crabs. J Exp Mar Biol Ecol 22:101-111

Minello T (1999) Nekton densities in shallow estuarine habitats of Texas and Louisiana and the identification of essential fish habitat. In: Benaka LR (ed) Fish habitat: essential fish habitat and rehabilitation. American Fisheries Society, Bethesda, MD, p 43-75

Moran NA, Whitham TG (1988) Population fluctuations in complex life cycles: an example from Pemphigus aphids. Ecology 69:1214-1218

Nillson JA (1994) Energetic bottle-necks during breeding and the reproductive cost of being too early. J Anim Ecol 63: 200-208

Orth RJ, Heck KL Jr, van Montfrans J (1984) Faunal communities in seagrass beds: a review of the influence of plant structure and prey characteristics on predator-prey relationships. Estuaries 7:339-350

Persson L, Greenberg LA (1990) Juvenile competitive bottlenecks: the perch (Perca fluviatilis)-roach (Rutilis rutilis) interaction. Ecology 71:44-56

Provenzano AJ Jr (1960) Notes on Bermuda hermit crabs (Crustacea: Anomura). Bull Mar Sci Gulf Caribb 10:117-124

Shih HT, Mok HK (2000) Utilization of shell resources by the hermit crabs Calcinus lateens and Calcinus gaimardii at Kenting, southern Taiwan. J Crustac Biol 20:786-795

Unger PA, Lewis JWM (1991) Population ecology of a pelagic fish, Xenomelaniris venezuelae (Atherinidae), in Lake Valencia, Venezuela. Ecology 72:440-456

Vance RR (1972) Competition and mechanism of coexistence in three sympatric species of intertidal hermit crabs. Ecology 53:1062-1074

Von Ende CN (1993) Repeated-measures analysis: growth and other time-dependent measures. In: Scheiner SM, Gurevitch J (eds) Design and analysis of ecological experiments. Chapman \& Hall, New York, p 113-137

Wahle RA, Steneck RS (1991) Recruitment habitats and nursery grounds of the American lobster Homarus americanus: a demographic bottleneck? Mar Ecol Prog Ser 69:231-243

Weins JA (1977) On competition in variable environments. Am Sci 65:590-597

Werner EE (1986) Species interactions in freshwater fish communities. In: Diamond J, Case TJ (eds) Community ecology. Harper \& Row, New York, p 344-358

Worcester SE, Gaines SD (1997) Quantifying hermit crab recruitment rates and megalopal shell selection on waveswept shores. Mar Ecol Prog Ser 157:307-310

Zar JH (1996) Biostatistical analysis, 3rd edn. Prentice-Hall, Upper Saddle River, NJ

Submitted: October 21, 2003; Accepted: April 6, 2004

Proofs received from author(s): July 20, 2004 